\title{
Learner-Driven Synthesis of Assessment Data: Engaging and Motivating Residents in Their Milestone-Based Assessments
}

\author{
Daniel J. Sklansky ${ }^{1}$ · John G. Frohna ${ }^{1}$ - Daniel J. Schumacher ${ }^{2}$
}

Published online: 9 January 2017

(C) International Association of Medical Science Educators 2017

\begin{abstract}
Competency-based medical education empowers learners to use self-assessment to monitor progress and to improve function. Given the difficulties inherent in self-assessment, we propose an externally calibrated, but residentowned system to facilitate resident involvement in assessment while minimizing the unreliability of self-assessment. Resident-driven synthesis of assessment data applies selfdetermination theory to foster residents' intrinsic motivation to improve by involving them in all the steps in the assessment process. Residents would review data, assign milestone levels, complete a program-specific assessment template, and discuss their findings with the clinical competency committee. Inclusion and empowerment of residents could benefit learners and programs alike.
\end{abstract}

Keywords Clinical competency committee .

Self-determination theory · Self-assessment .

Competency-based medical education $\cdot$ Resident assessment

The renewed focus on making the paradigmatic shift toward competency-based medical education (CBME) brought about by the milestone movement provides a new energy and framework for fostering learner-driven assessment and improvement. Indeed, early studies have shown benefits of the milestone system, including resident reports of increased understanding of their performance and ability to focus on future

Daniel J. Sklansky

djsklansky@pediatrics.wisc.edu

1 University of Wisconsin School of Medicine and Public Health, 600 Highland Avenue H4/418, Madison, WI 53792, USA

2 Cincinnati Children's Hospital Medical Center, 3333 Burnet Avenue, Cincinnati, OH 45229, USA goals $[1,2]$. These successes are foundational to CBME, in which learners are intended to be the driving force in their development, and raise the question of what other ways milestones can enable shifts that place learners in control of their learning [3]. We believe that learner-driven synthesis of assessment data, in which residents take primary responsibility for synthesizing their assessment data and assigning milestone levels, could be the foundation for further self-directed learning and self-regulation.

Figure 1 shows the theoretical framework around residentdriven synthesis of assessment data, which has selfassessment at its core. However, there is potential concern about whether self-assessment using milestones will help to inform resident progress or to facilitate self-directed learning skills. Research over the past decade has shown that selfassessment may encourage some residents to improve their awareness of deficiencies, create individualized learning plans, and bolster specific knowledge areas [4-9]. Unfortunately, self-assessment is fraught with inaccuracy and varies depending on the setting, content, and learner perspective [10-12]. Lower performing learners may not have insight into their low performance; conversely, higher performing learners may be more aware of their deficits than their strengths $[11,13,14]$. A few studies with very specific learner types and environments have shown good correlation between expert assessments and learner self-assessments, but these have been the exception rather than the rule [15-19]. Furthermore, the success reported in these environments may be due to a focus on self-monitoring rather than global self-assessment [20]. Finally, several small trials examining the use of milestones in resident self-assessment have shown mixed correlation with faculty assessments $[19,21,22]$.

With the concerns around self-assessment, it is reasonable to question its role in a program of global assessment. While it can serve as an important tool for encouraging resident 
Fig. 1 Theoretical framework around resident-driven synthesis of assessment data
Competency-based Medical Education

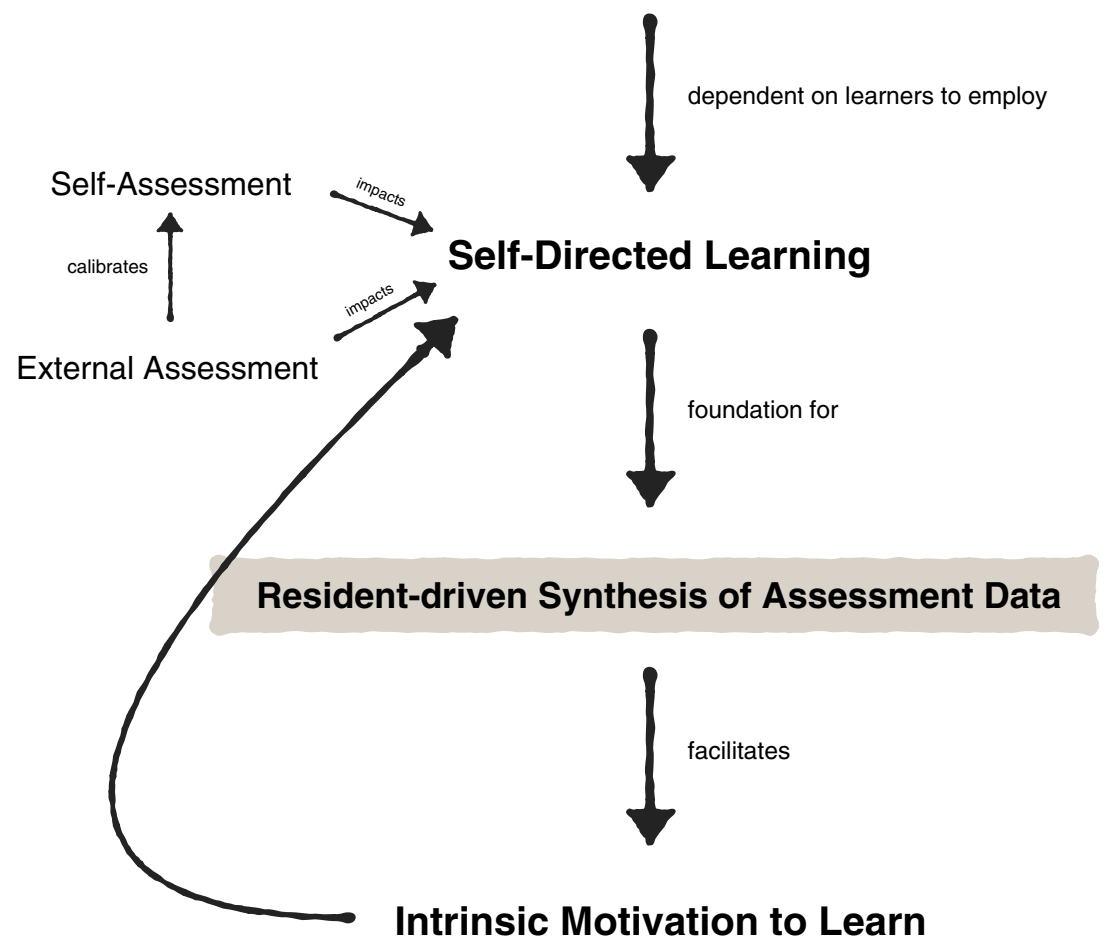

improvement, it is also an unreliable measure of competence. How, then, do we capitalize on the positives of selfassessment without falling prey to its deficiencies in defining the process of learner-driven synthesis of assessment data? As advocated by others, we believe that informed self-assessment is the key [5, 10, 20]. Residents should assess themselves using the milestones, but their self-assessments should be calibrated by external assessment. As detailed below, we believe the synthesis activity performed by the resident should not only utilize all assessment data the program possesses (e.g., assessment data that is external to the resident) but also be discussed with and calibrated by the program's clinical competency committee (CCC). To our knowledge, this is not a common practice in the milestone-based assessment era. Prior studies looking at this type of informed self-assessment (providing residents with external feedback for the sake of synthesizing assessments) have found that it minimizes the flaws inherent in primary self-assessment reliability while capturing the value of learner investment in the assessment process $[5,7,23]$.

\section{Resident-Driven Synthesis of Assessment Data: Benefits for Residents}

Learner-driven synthesis of assessment data provides several important benefits to residents. First, empowering residents with the primary responsibility for synthesizing their assessment data and tracking their progression through the milestones helps them better understand their developmental trajectory and hopefully increases initiative and understanding for continued improvement, consistent with the intent of CBME [3]. Second, resident involvement in the synthesis of assessments at semi-annual intervals provides transparency into a potentially nebulous system of CCC reviews and milestone assignments. This enhanced understanding of and engagement in the process would hopefully further empower residents to take charge of their own professional development. Third, this approach is consistent with how individuals learn best; self-determination theory (SDT) proposes that attending to a sense of autonomy, competence, and relatedness in learners drives them to become intrinsically (as opposed to extrinsically) motivated in their learning [24]. Stated differently, when learners are allowed to make decisions of their own volition, feel competent in their knowledge and abilities, and feel connected in their environment, they are more likely to be internally motivated to strive to perform at more advanced competency levels [25, 26]. Indeed, early evidence suggests the efficacy of SDT-based education for medical learners [27, $28]$.

Resident-driven synthesis of assessment data attends to all three components of SDT. Allowing residents to be the first individuals to provide their summative assessment promotes a sense of autonomy. Without this step, they are solely responding to an external assessment completed by the CCC that may feel inaccurate based on what they know about 
themselves, and unchangeable as a CCC decision can seem quite final. The process of resident-driven synthesis of assessment data also promotes a sense of competence because it affords residents the opportunity to provide information that is important to assigning milestone levels that they may know best. For example, the residency program and CCC members may not know the full extent of advocacy or quality improvement work that residents have completed, because these are areas outside of traditionally monitored residency activities during which most assessment information is collected. In this situation, the resident may have the most robust information for assigning milestones focused on these competencies. Allowing the resident to present this data, rather than utilizing the program's "best guess" allows the resident to not only present his competence but also feel competent in doing so. Finally, resident-driven synthesis of assessment data promotes a sense of relatedness because it places residents in a position to work with the $\mathrm{CCC}$ and program rather than receiving their milestone assignments from closed-door meetings. This also fosters relatedness because it demonstrates the value that CCC members place in residents to have an active, central role in producing a final assessment of their performance. By attending to these three tenets of SDT, resident-driven synthesis of assessment data will hopefully increase residents' intrinsic motivation to reflect on their ongoing performance and continual improvement efforts. It has been proposed that providing any feedback inherently opposes the principles of SDT [29]. However, we believe that by tasking residents with an SDT-supported process and using it to synthesize their assessments, it is possible to overcome the extrinsic and potentially ego-impacting nature of feedback.

\section{Resident-Driven Synthesis of Assessment Data: Benefits for Programs}

While there are many benefits of learner-driven synthesis of assessment data for residents, there are benefits for training programs as well. Perhaps most notably, this process shares the time consuming, hard work of synthesizing resident assessment data with someone other than CCC members and the program. It is important to remember that this is not a goal of learner-driven synthesis but rather a positive unintended consequence. Another benefit for the program is that this process will make residents more familiar with the fine details of physician development that are delineated in the milestones, which will, in turn, enhance the quality of the assessments they complete for peers and faculty. Finally, as noted in the benefits for residents, resident-driven synthesis allows residents to provide data that may otherwise have remained unknown to the program that is important in making assessments and in assigning milestone levels.

\section{What Learner-Driven Synthesis of Assessment Data Looks Like in Practice}

The details of a learner-driven synthesis of an assessment data program will vary based on the needs, structure, and philosophy of individual programs, but we believe there are common characteristics to consider, as shown in Fig. 2. First, residents should complete a self-assessment based on the milestones. This provides a starting point for their synthesis and orients them to the topics and contents of the milestones deemed germane for their specialty. Residents should then review their portfolio of assessment data with sufficient time (e.g., 1 month) prior to CCC assessment meetings. The portfolio should include all assessment data possessed by the program, along with program expectations for minimum milestone achievement based on the year of training. Ideally, the program-collected data would be from a range of sources, types, and individuals, including but certainly not limited to numerical- or milestone-based assessments, all positive and constructive comments from non-peers, blinded comments from peers, conference attendance records, duty hour logs, in-training exam scores, and non-physician assessment information from nurses or patients and families [30].

Next, to assist residents in assembling external assessments and data into a synthesized format to inform milestone level assignments, they should be provided with a template for synthesis and examples of prior CCC-finalized documents used by the program. A CCC member assigned to review the resident should be available for questions, especially when residents are new to this process. We advocate for a synthesis template that includes an area for documenting data from rotation assessment forms that fall substantially above or below program expectations. This will be helpful in identifying major areas of notable development as well as areas of focus for future development.

It is important for inputs to be gathered manually by the resident from their assessment information, rather than being automatically populated by system software. Manually documenting milestone score outliers and collating assessment themes would serve to calibrate the resident to assessments in a milestone-based manner. This process can be likened to the exercise of collecting and summarizing vital signs on patients before daily rounds. Manual review and recording of information during pre-rounding helps residents learn what is normal, sparks them to think about outliers and trends, and should prompt them to consider the data in the context of the patient. Milestone score review would function similarly to reviewing vital signs and could be explained as such, with the purpose of identifying trends of improvement or stagnation. When residents briefly review patient data but do not take the time to manually collect and summarize it because they know it to be easily accessible, they may not gain as much understanding about the patient. Similarly, programs 
Fig. 2 Common characteristics to consider in a resident-driven synthesis of assessment data program
1) Complete self-assessment

2) Review portfolio of assessment data from program

3) Assemble external assessment data into synthesized format

4) Reflect on missing data that is needed to assign milestone levels for all competencies and determine if resident possesses data/information that can inform those milestone assignments

5) Document progress in completing program requirements that fall outside traditional rotations (e.g., scholarly projects, Ql projects, advocacy work)

6) Review milestone self-assessment (step 1) and adjust based on external assessment data and then construct a synthesis statement summarizing progress from the last review cycle, accomplishments, areas of notable development, areas for future development, and specific plans for improvement

7) Present synthesis to clinical competency committee (CCC) and make additional modifications as needed

8) With CCC, determine overall classification of current developmental progress should be careful not to automate too much of the selfassessment process in order for the residents to learn from the activity.

After reviewing assessment data from the program, residents should reflect on what information was missing that was important for assigning milestone levels. They should then determine what data they can provide to inform these areas and document that for inclusion in their synthesis. Residents should also document their progress in completing program requirements that fall outside of traditional clinical rotations, such as advocacy, quality improvement, and scholarly projects. Having reviewed and documented all available assessment information, residents should next review their milestone self-assessments, adjust milestone levels as appropriate based on the external assessment information they have reviewed, and construct a synthesis statement. This statement summarizes their progress from the last review cycle, accomplishments, areas of notable development, areas for future development, and includes at least a few specific plans for improvement.

Once complete, residents should present their synthesis to the CCC. Continuing to attend to the troubles with selfassessment and the importance of external calibration, CCC members and the resident should have a bidirectional conversation regarding the resident's conclusions, coming to an agreement about any changes to be made in the synthesis provided by the resident. The CCC member assigned to review the resident should be prepared to discuss any discrepancies between the CCC's synthesis and the resident's synthesis. Thus, it would be helpful for this CCC member to have the resident's synthesis prior to the resident presenting it at the CCC meeting. While the
CCC can have the final word in resident assessment, it should be expected to explain its conclusions to the resident via live dialog in cases of disagreement.

After discussing and finalizing all assessment data, milestone level assignments, areas of notable development, and areas for future development, residents and CCC members should agree on an overall classification of current developmental progress. We recommend a framework such as on track, on track except for a specific area of concern, or globally not on track based on criterion standards identified by the residency program. For residents in need of special attention or remediation, it would likely be less surprising and more palatable for those revelations to come through this process of informed self-assessment as opposed to being handed down from a committee without warning. Ideally, residents needing remediation or additional help with development should help to construct their own learning plans.

\section{Future Directions}

Although learner-driven synthesis of assessment data presents a steep learning curve for the first CCC implementation cycle and for new residents each academic year, it provides hope for great rewards. With experience and careful application of SDT principles by educational leaders, resident involvement could lead to intrinsic motivation for self-directed learning and selfassessment, which are both foundational to CBME. Inclusion in the process could also encourage learners to more fully understand their development progress and use their 
additional insight to create more robust individualized learning plans. CCC reviewers would learn about resident perceptions of written assessments and feedback, and have another perspective available in the formulation of the ultimate synthesis of resident progress at the end of each session. As a result of increased awareness from faculty and learners, a positive feedback loop of improved competency-based assessments could occur throughout the department. This all could come together to achieve the goal of providing a structure and environment conducive to fostering the growth of master learners who are ready to drive effective learning and improvement over the course of their careers [31].

\section{References}

1. Hicks PJ, Margolis M, Poynter SE, Chaffinch C, Tenney-Soeiro R, Turner TL, et al. The pediatrics milestones assessment pilot: development of workplace-based assessment content, instruments, and processes. Acad Med. 2016; doi:10.1097/ACM.0000000000001057.

2. Li ST, Tancredi DJ, Burke AE, Guillot A, Guralnick S, Trimm RF, et al. Self-assessment on the competencies and reported improvement priorities for pediatrics residents. J Grad Med Educ. 2012;4(4):445-53. doi:10.4300/jgme-d-12-00009.1.

3. Carraccio C, Wolfsthal SD, Englander R, Ferentz K, Martin C. Shifting paradigms: from Flexner to competencies. Acad Med. 2002;77(5):361-7.

4. Li ST, Paterniti DA, Tancredi DJ, Burke AE, Trimm RF, Guillot A, et al. Resident self-assessment and learning goal development: evaluation of resident-reported competence and future goals. Acad Pediatr. 2015;15(4):367-73. doi:10.1016/j.acap.2015.01.001.

5. Probyn L, Lang C, Tomlinson G, Bandiera G. Multisource feedback and self-assessment of the communicator, collaborator, and professional CanMEDS roles for diagnostic radiology residents. Can Assoc Radiol J. 2014;65(4):379-84. doi:10.1016/j.carj.2014.04.003.

6. Peterson LE, Blackburn B, King MR. Completing self-assessment modules during residency is associated with better certification exam results. Fam Med. 2014;46(8):597-602.

7. Plant JL, Corden M, Mourad M, O'Brien BC, van Schaik SM. Understanding self-assessment as an informed process: residents' use of external information for self-assessment of performance in simulated resuscitations. Adv Health Sci Educ Theory Pract. 2013;18(2):181-92. doi:10.1007/s10459-012-9363-2.

8. Bounds R, Bush C, Aghera A, Rodriguez N, Stansfield RB, Santen SA. Emergency medicine residents' self-assessments play a critical role when receiving feedback. Acad Emerg Med. 2013;20(10): 1055-61. doi:10.1111/acem.12231.

9. Francois J. Improving family medicine residents' written communication using a self-assessment process. Can Med Educ J. 2012;3(1):e64-8.

10. Eva KW, Regehr G. Self-assessment in the health professions: a reformulation and research agenda. Acad Med. 2005;80(10 Suppl):S46-54.

11. Regehr G, Eva K. Self-assessment, self-direction, and the selfregulating professional. Clin Orthop Relat Res. 2006;449:34-8. doi:10.1097/01.blo.0000224027.85732.b2.

12. Sargeant J, Eva KW, Armson H, Chesluk B, Dornan T, Holmboe E, et al. Features of assessment learners use to make informed selfassessments of clinical performance. Med Educ. 2011;45(6):63647. doi:10.1111/j.1365-2923.2010.03888.x.

13. Davis DA, Mazmanian PE, Fordis M, Van Harrison R, Thorpe KE, Perrier L. Accuracy of physician self-assessment compared with observed measures of competence: a systematic review. JAMA. 2006;296(9):1094-102. doi:10.1001/jama.296.9.1094.

14. Eva KW, Cunnington JP, Reiter HI, Keane DR, Norman GR. How can I know what I don't know? Poor self assessment in a welldefined domain. Adv Health Sci Educ Theory Pract. 2004;9(3): 211-24. doi:10.1023/B:AHSE.0000038209.65714.d4.

15. Hadley C, Lam SK, Briceno V, Luerssen TG, Jea A. Use of a formal assessment instrument for evaluation of resident operative skills in pediatric neurosurgery. J Neurosurg Pediatr. 2015: 1-8. doi:10.3171/2015.1.peds14511.

16. Trajkovski T, Veillette C, Backstein D, Wadey VM, Kraemer B. Resident self-assessment of operative experience in primary total knee and total hip arthroplasty: is it accurate? Can J Surg. 2012;55(4):S153-7. doi:10.1503/cjs.035510.

17. Schatz A, Kogan B, Feustel P. Assessing resident surgical competency in urology using a global rating scale. J Surg Educ. 2014;71(6):790-7. doi:10.1016/j.jsurg.2014.03.012.

18. Kruger J, Dunning D. Unskilled and unaware of it: how difficulties in recognizing one's own incompetence lead to inflated self-assessments. J Pers Soc Psychol. 1999;77(6):1121-34.

19. Goldflam K, Bod J, Della-Giustina D, Tsyrulnik A. Emergency medicine residents consistently rate themselves higher than attending assessments on ACGME milestones. West J Emerg Med. 2015;16(6):931-5. doi:10.5811/westjem.2015.8.27247.

20. Eva KW, Regehr G. Exploring the divergence between selfassessment and self-monitoring. Adv Health Sci Educ Theory Pract. 2011;16(3):311-29. doi:10.1007/s10459-010-9263-2.

21. Bradley KE, Andolsek KM. A pilot study of orthopaedic resident selfassessment using a milestones' survey just prior to milestones implementation. Int J Med Educ. 2016;7:11-8. doi:10.5116/ijme.5682.6dfd.

22. Weizberg M, Bond MC, Cassara M, Doty C, Seamon J. Have first-year emergency medicine residents achieved level 1 on care-based milestones? J Grad Med Educ. 2015;7(4):589-94. doi:10.4300/jgme-d-1400590.1 .

23. Mann K, van der Vleuten C, Eva K, Armson H, Chesluk B, Dornan $\mathrm{T}$, et al. Tensions in informed self-assessment: how the desire for feedback and reticence to collect and use it can conflict. Acad Med. 2011;86(9):1120-7. doi:10.1097/ACM.0b013e318226abdd.

24. Ryan RM, Deci EL. Intrinsic and extrinsic motivations: classic definitions and new directions. Contemp Educ Psychol. 2000;25(1):54-67. doi:10.1006/ceps.1999.1020.

25. Kusurkar RA, Ten Cate TJ, Vos CM, Westers P, Croiset G. How motivation affects academic performance: a structural equation modelling analysis. Adv Health Sci Educ Theory Pract. 2013;18(1):57-69. doi:10.1007/s10459-012-9354-3.

26. Kusurkar RA, Croiset G, Galindo-Garre F, Ten Cate O. Motivational profiles of medical students: association with study effort, academic performance and exhaustion. BMC Med Educ. 2013;13:87. doi:10.1186/1472-6920-13-87.

27. Orsini $\mathrm{C}$, Evans $\mathrm{P}$, Jerez $\mathrm{O}$. How to encourage intrinsic motivation in the clinical teaching environment?: a systematic review from the self-determination theory. J Educ Eval Health Prof. 2015;12:8. doi:10.3352/jeehp.2015.12.8.

28. Kusurkar RA, Croiset G. Autonomy support for autonomous motivation in medical education. Med Educ Online. 2015;20:27951. doi:10.3402/meo.v20.27951.

29. ten Cate OT. Why receiving feedback collides with self determination. Adv Health Sci Educ Theory Pract. 2013;18(4):845-9. doi:10.1007/s10459-012-9401-0.

30. van der Vleuten CP, Schuwirth LW, Driessen EW, Govaerts MJ, Heeneman S. 12 tips for programmatic assessment. Med Teach. 2014:1-6. doi:10.3109/0142159X.2014.973388.

31. Schumacher DJ, Englander R, Carraccio C. Developing the master learner: applying learning theory to the learner, the teacher, and the learning environment. Acad Med. 2013;88(11):1635-45. doi:10.1097/ACM.0b013e3182a6e8f8. 